\title{
Transtornos mentais comuns em agricultores, relação com agrotóxicos, sintomas físicos e doenças preexistentes
}

\author{
Pâmela Vione Morin \\ Eniva Miladi Fernandes Stumm \\ Sociedade Educacional Três de Maio-RS-SETREM
}

\begin{abstract}
Resumo
Objetivo: O objetivo do presente trabalho foi relacionar os transtornos mentais comuns em agricultores com o uso de agrotóxicos, sintomas físicos, psíquicos e doenças preexistentes. Método: Estudo transversal, descritivo e analítico, com 361 agricultores que utilizam agrotóxicos. Os instrumentos de coleta de dados foram: SRQ-20 e formulário de identificação, dados sociodemográficos e clínicos. Resultados: 173 (47,9\%) participantes da pesquisa apresentaram transtorno mental comum, sintomas físicos, emocionais e doenças preexistentes. Existe relação estatisticamente significativa $(\mathrm{p}<0,01)$ entre tempo de agricultura, exposição, doenças preexistentes com os transtornos mentais comuns. Conclusão: A utilização de agrotóxicos compromete a saúde física e psíquica do agricultor.
\end{abstract}

Palavras-chave: Agroquímicos; Riscos Ocupacionais; Saúde do trabalhador; Agricultores.

\section{Common mental disorders in farmers, the relationship with pesticides, physical symptoms and preexistent diseases}

\begin{abstract}
Objective: The objective of the present study was to relate the common mental disorders in farmers with use of pesticides, physical and psychological symptoms and preexisting diseases. Method: Cross-sectional, descriptive and analytical study, with 361 farmers that use pesticides. The data collection instruments were: SRQ-20 and identification form, socio-demographic and clinic data. Results: 173 (47.9\%) participants had common mental disorder, physical and emotional symptoms, and preexisting diseases. There is a statistically significant relationship $(\mathrm{p}<0.01)$ between time of agriculture, exposure and preexisting diseases with common mental disorders. Conclusion: The use of pesticides compromises the physical and mental health of the farmer.
\end{abstract}

Keywords: Agrochemicals; Occupational Risks; Worker's health; Farmers.

\section{Transtornos mentales comunes en agricultores, relación con los agroquímicos, síntomas físicos y enfermedades preexistentes}

\section{Resumen}

Objetivo: El objetivo del presente trabajo fue relacionar los trastornos mentales comunes en los agricultores con uso de agroquímicos, síntomas físicos, psicológicos y enfermedades preexistentes. Método: Transversal, descriptivo y analítico, con 361 agricultores que usan agroquímicos. Los instrumentos de recolección de datos fueron: SRQ-20 y formulario de identificación, sociodemográfico y clínico. Resultados: 173 (47,9\%) participantes del estudio presentaron trastorno mental común, síntomas físicos, emocionales y enfermedades preexistentes. Existe una asociación estadísticamente significativa $(p<0,01)$ entre tiempo en la agricultura, exposición y enfermedades preexistentes con trastornos mentales comunes. Conclusión: El uso de agroquímicos compromete la salud física y mental del agricultor

Palabras clave: Agroquímicos; Riesgos laborales; Salud laboral; Agricultores. 


\section{Introdução}

O advento da modernização repercutiu em diversos espaços de produção, inclusive na agricultura. Esse cenário contemporâneo exige constante investimento em tecnologias, expressas na utilização de agroquímicos. Essa prática realizada pelos agricultores parte do princípio de que a não utilização dos respectivos produtos compromete a produção, com a presença de insetos, ervas daninhas e fungos. Assim, o uso intenso de agrotóxicos apresenta-se como solução tecnológica para os problemas enfrentados na agricultura, ocasionados pelas pragas agrícolas (Abreu \& Alonzo, 2014).

O investimento em tecnologias ocorreu no Brasil entre as décadas de 1960 e 1980, quando teve início a chamada revolução verde que contou com o apoio de medidas governamentais articuladas a fim de promover $\mathrm{o}$ acesso do agricultor à mecanização e a utilização de agrotóxicos. Nesse contexto, destacaram-se o Sistema Nacional de Créditos Rurais, o qual atrelava o acesso ao crédito à compra de maquinários e insumos agrícolas, e o Programa Nacional de Defensivos Agrícolas que financiava a criação de empresas nacionais e instalação de empresas internacionais deste setor no país. Esse incentivo se perpetua até os dias de hoje através de isenções fiscais concedidas às indústrias químicas produtoras, a fim de movimentar lucros (Londres, 2011).

Neste percurso de modernização da agricultura, fazse necessário destacar as incongruências que ficaram como plano de fundo deste cenário. As profundas marcas deixadas na sociedade brasileira apontam para um aumento estrondoso na produtividade e lucro. Inegável melhora na economia do país, porém não foi condicionante para o bem-estar geral dos trabalhadores rurais.

O progresso tecnológico de produção, excluiu muitos agricultores e privilegiou latifundiários, ao mesmo tempo em que silenciou os movimentos dos trabalhadores rurais, acentuou concentrações de terra nas mãos de poucos, impulsionando o desemprego rural e consequentemente o êxodo rural. Nesta lógica, a modernização agrícola fortaleceu as elites sociais, o desnível entre o grande e o pequeno produtor, bem como a incompatibilidade com o conceito de modernização aos pequenos produtores (Silva \& Botelho, 2014).

Esse modelo agrícola vigente ainda aponta outro aspecto impactante, a prática em desconformidade com as prerrogativas de sustentabilidade aplicadas na produção agroecológica. Assim, o modelo que temos, voltado ao uso da tecnologia se distancia de uma produção voltada a proteção dos recursos naturais bem como, da saúde de todos os envolvidos, produtores e consumidores. Desta forma, cria-se uma desigualdade quando comparada as formas de produção e as rentabilidades, visualiza-se a disparidade com o pequeno produtor que encontra dificuldades em produzir e se manter no mercado (Nodari \& Guerra, 2014). Essa situação, faz com que a agricultura familiar enfraqueça e se encontre em importante dificuldade de desenvolvimento e de viabilidade social e econômica, na mesma proporção que enfatiza o uso de agrotóxicos na prática agrícola dos grandes produtores para fins de desenvolvimento social e econômico.

A partir desta forma de produção com o uso da tecnologia, é que o Brasil encontra-se em expansão no consumo de agrotóxicos, quando em 2008 assumiu a liderança mundial na utilização dessas substâncias (Ferreira \& Viana, 2016). Salienta-se que o estado do Rio Grande do Sul detém o consumo de quase o dobro da média nacional, comparada, especificamente, na safra de 2009/2010 quando utilizou 85 milhões de litros, o equivalente ao consumo de 8,3 litros por gaúcho/ano de agrotóxico, enquanto a média nacional em 2011 foi de 4,5 litros por pessoa (Cigana, 2016; Dossiê Abrasco, 2012).

Esses dados revelam as consequências para população geral envolvida pelo consumo cotidiano de alimentos contaminados por agrotóxicos, que representam $70 \%$ dos alimentos in natura consumidos no Brasil, e destes agroquímicos utilizados 28\% apresentam ingredientes ativos não autorizados, esses dados foram divulgados pelo Dossiê Abrasco, que também destaca, que mais da metade dos agrotóxicos usados no Brasil são banidos em países da União Europeia e nos Estados Unidos (Dossiê Abrasco, 2012).

Para uma compreensão mais detalhada do comprometimento da alimentação da população geral, a Agência Nacional de Vigilância Sanitária, divulgou o nível médio de contaminação por agrotóxicos presentes em algumas culturas, pimentão $91,8 \%$, morango $63,4 \%$, pepino $57,4 \%$, alface $54,2 \%$, cenoura $49,6 \%$, abacaxi $32,8 \%$, beterraba $32,6 \%$ e mamão $30,4 \%$ (Anvisa, 2011).

Diante deste contexto, verifica-se o grave problema de saúde pública que envolve a todos nós e o descaso por parte dos órgãos governamentais, federais, estaduais e municipais fiscalizadores, como Ministério do Meio Ambiente IBAMA, Ministério da Agricultura, Ministério da Saúde ANVISA, que se fazem omissos diante da problemática, delongam a suspensão destas substâncias malignas à população e benignas às indústrias. Neste sentido, cada órgão teria suas competências definidas pela Lei 7.802/1989. Competências Federias, seriam, controlar e fiscalizar 
os estabelecimentos de produção, importação e exportação de agrotóxicos. Para os Estados ficaria a responsabilidade de fiscalizar o uso, consumo, comércio, armazenamento e transporte. E as municipais deveriam legislar supletivamente sobre o uso e o armazenamento de agrotóxicos. Esses seriam os responsáveis pela fiscalização e cuidado da saúde e ambiente, mas as normativas se distanciam da prática, e desta forma, o consumo de agrotóxicos tende a aumentar.

Nesta perspectiva, dados divulgados pela Associação Brasileira da Indústria Química, destacam o aumento de $13 \%$ nas vendas de agrotóxicos no Brasil, responsável pela movimentação de bilhões de reais. Nesse ínterim, os agrotóxicos fomentam além de lucros e rankings, prejuízos à saúde do trabalhador, em constante risco ocupacional (Abiquim, 2014).

A saúde do trabalhador se configura como um campo de conhecimento e de práticas que tem como foco o estudo, a análise e a compreensão da relação entre trabalho-saúde-doença. Consideram-se assim condicionantes para tais concepções as questões sociais, as condições e organizações do trabalho bem como, a subjetividade de cada trabalhador (Merlo, Bottega \& Perez, 2014). A partir desta premissa, elenca-se o uso de agrotóxico como comprometedor da saúde do trabalhador, e verifica-se que a própria nomenclatura já é sugestiva, portanto, representa ameaças à saúde humana, com efeitos deletérios a partir das intoxicações, características individuais, princípio ativo, forma de exposição e tempo de trabalho na agricultura. No Brasil, destaca-se que o agrotóxico mais utilizado de acordo com o princípio ativo é o glifosato, herbicida cancerígeno em seres humanos (Brasil, 2016).

A exposição a agrotóxicos aliada ao uso indiscriminado dos mesmos, é explicitado na literatura como responsável por diversos sintomas, doenças físicas e emocionais. Os sintomas frequentes causados por intoxicações agudas são identificados por náuseas, cefaléia, irritabilidade, desorientação, dores no peito, vertigem, taquicardia, fadiga, tontura, irritação na pele, olhos, mucosas e dificuldade respiratória (Menegat \& Fontana, 2010; Mascarenha \& Pessoa, 2013).

Em relação à intoxicação crônica, os efeitos emergem da exposição continuada, em longo prazo. Os sintomas iniciam tardiamente e são expressos por comprometimentos irreversíveis, na maioria dos casos. Neste contexto, destaca-se o surgimento de câncer em agricultores, com origem nos sistemas digestório, reprodutor masculino, imunológico, endócrino, tegumentar, respiratório e urinário (Andreotti et al., 2009; Miranda, 2015).

A literatura enfatiza outros agravos à saúde, relacionada à exposição e intoxicação crônica aos agrotóxicos, revelados em doenças cardiovasculares, morbidade respiratória, doença de Parkinson, transtornos da visão, ansiedade, depressão, confusão mental, hipertensão arterial e efeitos neurológicos diversos, dentre eles, suicídio (Benachour \& Séralini, 2008; Fareed et al., 2013; Albuquerque et al., 2015; Furlong et al., 2015; Sekhotha, Monyeki, \& Sibuyi, 2016).

Neste enredo com expressivos comprometimentos à saúde do agricultor, ressaltam-se os danos à saúde mental desta população. Dentre eles está a ocorrência de transtornos mentais comuns, manifestados por queixas sintomáticas depressivas, ansiosas, subjetivas e isoladas, que compreendem insônia, irritabilidade, nervosismo, fadiga, dores de cabeça, esquecimento e falta de concentração (Goldberg \& Huxley, 1992).

Os agrotóxicos utilizados na agricultura apresentam prejuízos à saúde mental pela sua capacidade neurotóxica. Estudos destacam dentre os agravos, a prevalência de transtornos mentais comuns nesta população, os quais evidenciam a relação entre a exposição e o transtorno (Albuquerque et al., 2015; Faria et al., 2014; Lima, 2015).

Diante do exposto, a partir do reconhecimento dos efeitos danosos dos agrotóxicos à saúde do trabalhador rural busca-se com o presente artigo relacionar transtornos mentais comuns em agricultores com o uso de agrotóxicos, sintomas físicos, psíquicos e doenças preexistentes.

\section{Método}

Trata-se de estudo com delineamento transversal, descritivo e analítico. Participaram deste 361 agricultores do interior do município de Três de Maio, localizado no noroeste do estado do Rio Grande do Sul, região em que se produz soja, milho e trigo. O estudo foi delimitado ao gênero masculino, por serem eles os envolvidos na produção e expostos no contato direto aos agrotóxicos. Destaca-se que os participantes não trabalham com agricultura familiar ou produção agroecológica e são considerados pequenos produtores, dos quais $63,7 \%$ tem até 25 hectares, $19,9 \%$ possui até 50 hectares, $10,5 \%$ até 100 hectares, $3,9 \%$ com propriedades entre 100 à 200 hectares e 1,9\% possuem a cima de 200 hectares.

A coleta de dados foi realizada no período de janeiro a março de 2016, em dois sindicatos rurais (230 trabalhadores) e os demais (131 trabalhadores) nos domicílios. Os trabalhadores rurais foram abordados de forma individual pela pesquisadora que apresentou a proposta do estudo e os convidou a participarem de forma voluntária. Mediante manifestação do interesse 
em participar na pesquisa, a pesquisadora explanou o Termo de Consentimento Livre e esclarecido - TCLE, que foi assinado em duas vias, uma delas em seu poder e outra do participante. Os trabalhadores que aceitaram integrarem-se à população estudada foram abordados em ambiente privativo a fim de preservá-los, garantir a qualidade e o sigilo das informações.

Os critérios de inclusão elencados foram os seguintes: aceitar assinar o Termo de Consentimento do estudo, residir no referido município, utilizar agrotóxicos na lavoura e ter idade mínima de18 anos. Os critérios de exclusão foram: não aceitar assinar o TCLE e apresentar algum prejuízo cognitivo, identificado pela não compreensão das informações contidas nos instrumentos de coleta de dados utilizados.

Para a coleta de dados, foram utilizados formulário com dados de identificação, sociodemográficos e clínicos, cuidados com a saúde, sintomas físicos e emocionais associados ao uso de agrotóxicos. Para a suspeição diagnóstica de transtornos mentais comuns, utilizou-se o instrumento SQR-20 (Self-Reporting Questionnarie), composto por crivo com 20 perguntas.

A análise dos dados foi realizada com o uso de estatística descritiva, analítica, com o auxílio do programa Statistical Package for Social Science (SPSS), versão 17.0.Foram aplicados o Coeficiente Alfa de Cronbach para verificar a consistência e a confiabilidade do instrumento, o teste $\mathrm{p}$ Qui-quadrado $\left(\chi^{2}\right)$ e exato de Fischer para verificar existência de associação entre as variáveis estudadas, consideradas estatisticamente significantes se $\mathrm{p}<0,01$ e a estatística descritiva, com média, desvio padrão, limite superior, inferior, range e tabelas cruzadas para apresentar os dados de forma clara e abrangente.
Para o rastreamento de transtornos mentais comuns analisou-se o SRQ-20, composto por vinte questões de respostas sim/não. Cada resposta afirmativa recebeu o valor de (1). Para análise das respostas considerou-se pontuação (0) para nenhuma probabilidade de transtornos mentais não psicóticos e (20) para extrema probabilidade. O ponto de corte foi de 7 pontos, assim, resultados acima deste, implicam em transtorno mental comum (Gonçalves,Stein \& Kapczinski, 2008).

Esta pesquisa contempla todos os aspectos éticos referidos na Resolução 466-2012, projeto de pesquisa aprovado por Comitê de Ética em Pesquisa sob CAAE 51397615.4.0000.5322.

\section{Resultados}

Participaram do estudo 361 agricultores, com idades entre 18 e 73 anos, com maior percentual na faixa etária de 40 a 60 anos incompletos, com média e desvio padrão de $50,02 \pm 11,11$, o que representa uma diferença de 55 anos. A maioria encontra-se neste labor em média e desvio padrão de $36,88 \pm 12,54$. Destacase a baixa escolaridade dos participantes da pesquisa, pois $61 \%$ deles cursou ensino fundamental incompleto. Quanto ao estado civil, mais de $80 \%$ são casados, conforme evidenciado na Tabela 1. Neste grupo, constata-se que $47,9 \%$, ou seja, 173 participantes apresentaram transtorno mental comum.

Sequencialmente, na Tabela 2 são apresentados o tempo de trabalho na agricultura dos participantes e uso de agrotóxicos, correlacionados com a ocorrência de transtorno mental comum. Nesta, verifica-se que existe uma relação significativa $(p<0,01)$ entre $o$ tempo de trabalho na agricultura e de exposição com os transtornos mentais comuns.

TABELA 1

Dados sociodemográficos de agricultores que utilizam agrotóxicos do município de Três de Maio.

\begin{tabular}{llcc}
\hline Dados sociodemográficos & & $n$ & $\%$ \\
\hline Estado Civil & Solteiro & 49 & 13,6 \\
& Casado/Companheira & 296 & 82,0 \\
& Separado/viúvo & 16 & 4,4 \\
& Menos que 40 & 66 & 18,3 \\
Idade & $40-60$ & 220 & 60,9 \\
& 60 ou mais & 75 & 20,8 \\
(Li; Ls; Range) & & $(18 ; 73 ; 55)$ & \\
(Média; Desvio padrão) & & $(50,02 ; 11,11)$ & \\
Escolaridade & Ensino Fundamental incompleto & 221 & 61,2 \\
& Ensino Fundamental completo & 57 & 15,8 \\
& Mais que Ensino Fundamental & 83 & 23,0 \\
Total & & 361 & 100 \\
\hline
\end{tabular}


TABELA 2

Tempo de agricultura e exposição a agrotóxicos e correlação ao SRQ-20 de agricultores que utilizam agrotóxicos do município de Três de Maio.

\begin{tabular}{|c|c|c|c|c|c|}
\hline \multirow{2}{*}{\multicolumn{2}{|c|}{ Tempo em anos }} & \multicolumn{2}{|c|}{$S R Q$} & \multirow{2}{*}{$\begin{array}{l}\text { Total } \\
N(\%)\end{array}$} & \multirow[b]{2}{*}{ p-valor } \\
\hline & & $\begin{array}{c}<7 \\
\mathrm{~N}(\%)\end{array}$ & $\begin{array}{c}\geq 7 \\
\mathrm{~N}(\%)\end{array}$ & & \\
\hline \multirow[t]{2}{*}{ Tempo de agricultura } & $<40$ & $109(63,7)$ & $62(36,3)$ & $171(100)$ & \multirow{2}{*}{0,0001} \\
\hline & $\geq 40$ & $79((41,6)$ & $111(58,4)$ & $190(100)$ & \\
\hline \multirow[t]{2}{*}{ Tempo de exposição } & $\leq 20$ & $115(59,3)$ & $79(40,7)$ & 194(100) & \multirow{2}{*}{0,002} \\
\hline & $>20$ & $73(43,7)$ & $94(56,3)$ & $167(100)$ & \\
\hline
\end{tabular}

Teste exato de Fisher's significativo para $\mathrm{p}<0,01$.

Ainda em relação aos dados contidos na Tabela 2, constata-se que dos agricultores que tem o referido transtorno, 36,3\% deles estão há menos de 40 anos na agricultura e 58,4\%, 40 anos ou mais. Em relação ao tempo de exposição, evidencia-se que $56,3 \%$ dos participantes da pesquisa, com mais de 20 anos em contato com agrotóxicos, apresentam transtorno mental comum e 40,7\%, com menos de 20 anos, igualmente.

Na Tabela 3, são explicitadas doenças preexistentes, referidas pelos participantes da pesquisa e relacionadas com o instrumento SRQ-20. Nesta, examina-se que existe uma relação significativa entre essas duas variáveis $(\mathrm{p}<0,01)$.

Conforme explicitado na Tabela 3, constata-se que $30,5 \%$ dos agricultores com transtorno mental comum, referiram ter e 17,5\% não, doenças preexistentes. Em contrapartida, $35,2 \%$ dos participantes que não referiu nenhuma doença, igualmente, não apresentou o referido transtorno mental. Evidencia-se também que as doenças mais mencionadas pelos trabalhadores com transtorno mental comum, em ordem decrescente, foram: câncer, depressão, gastrite, doença cardíaca e hipertensão.

TABELA 3

Doenças Preexistentes referidas e correlação com SRQ-20 de agricultores que utilizam agrotóxicos do município de Três de Maio.

\begin{tabular}{lccc}
\hline & & \multicolumn{2}{c}{$S R Q$} \\
Doenças Preexistentes* & $<7$ & $\geq 7$ & Total \\
\cline { 2 - 4 } & $N(\%)$ & $N(\%)$ & $N(\%)$ \\
\hline Sim & $61(16,9)$ & $110(30,5)$ & $171(47,4)$ \\
Não & $127(35,2)$ & $63(17,5)$ & $190(52,6)$ \\
Total & $188(52,1)$ & $173(47,9)$ & $361(100)$ \\
Doenças mencionadas & & & \\
Hipertensão & $41(41,4)$ & $58(58,6)$ & $99(100)$ \\
Depressão & $2(6,9)$ & $27(93,1)$ & $29(100)$ \\
Problema cardíaco & $7(35,0)$ & $13(65,0)$ & $20(100)$ \\
Gastrite & $6(30,0)$ & $14(70,0)$ & $20(100)$ \\
Câncer & - & $13(100)$ & $13(100)$ \\
DM & $6(60,0)$ & $4(40,0)$ & $10(100)$ \\
Problemas pulmonares & $1(20,0)$ & $4(80,0)$ & $5(100)$ \\
Coluna & $1(16,7)$ & $5(83,3)$ & $6(100)$ \\
Colesterol & $1(25,0)$ & $3(75,0)$ & $4(100)$ \\
Parkinson & $1(25,0)$ & $3(75,0)$ & $4(100)$ \\
Labirintite & - & $2(100)$ & $2(100)$ \\
Alergias & $2(66,7)$ & $1(33,3)$ & $3(100)$ \\
Enxaqueca & $1(50,0)$ & $1(50,0)$ & $2(100)$ \\
Ácido Úrico & $2(100)$ & - & $2(100)$ \\
Outra & $2(40,0)$ & $3(60,0)$ & $5(100)$ \\
\hline
\end{tabular}

* Teste Qui-quadrado relação significativa entre a existência de transtorno mental e doenças existentes $(\mathrm{p}=0,0001)$. 
TABELA 4

Sintomas recentes associados ao uso de agrotóxicos, segundo o SRQ-20, de agricultores que utilizam agrotóxicos do município de Três de Maio.

\begin{tabular}{|c|c|c|c|}
\hline \multirow[b]{2}{*}{ Sintomas } & \multicolumn{3}{|c|}{$S R Q$} \\
\hline & $\begin{array}{c}<7 \\
N(\%)\end{array}$ & $\begin{array}{c}\geq 7 \\
N(\%)\end{array}$ & $\begin{array}{l}\text { Total } \\
N(\%)\end{array}$ \\
\hline \multicolumn{4}{|l|}{ Sintomas Físicos } \\
\hline Dor de cabeça & $70(37,6)$ & $116(62,4)$ & $186(100)$ \\
\hline Irritação nos olhos & $76(41,1)$ & $109(58,9)$ & $185(100)$ \\
\hline Visão turva & $5(20,0)$ & $20(80,0)$ & $25(100)$ \\
\hline Lacrimejamento & $2(33,3)$ & $4(66,7)$ & $6(100)$ \\
\hline Lesões pele & $3(18,8)$ & $13(81,3)$ & $16(100)$ \\
\hline Tontura & $24(24,5)$ & $74(75,5)$ & $98(100)$ \\
\hline Náuseas & $9(21,4)$ & $33(78,6)$ & $42(100)$ \\
\hline Vomito & - & $8(100)$ & $8(100)$ \\
\hline Aumento de saliva & $4(36,4)$ & $7(63,6)$ & $11(100)$ \\
\hline Suor excessivo & $1(25,0)$ & $3(75,0)$ & $4(100)$ \\
\hline Tosse & $1(33,3)$ & $2(66,7)$ & $3(100)$ \\
\hline Boca seca & $32(29,1)$ & $78(70,9)$ & $110(100)$ \\
\hline Chiado no peito & $1(16,7)$ & $5(83,3)$ & $6(100)$ \\
\hline Falta de ar & $4(25,0)$ & $12(75,0)$ & $16(100)$ \\
\hline Dor abdominal & $1(9,1)$ & $10(90,9)$ & $11(100)$ \\
\hline Digestão difícil & $13(36,1)$ & $23(63,9)$ & $36(100)$ \\
\hline Tremores & - & $5(100)$ & $5(100)$ \\
\hline Diarreia & $1(16,7)$ & $5(83,3)$ & $6(100)$ \\
\hline Cansaço físico & $5(31,3)$ & $11(68,8)$ & $16(100)$ \\
\hline Coceira na pele & $4(26,7)$ & $11(73,3)$ & $15(100)$ \\
\hline Gastrite & - & $2(100)$ & $2(100)$ \\
\hline Espirros & $1(100)$ & - & $1(100)$ \\
\hline Sente-se mal com inseticida & - & $1(100)$ & $1(100)$ \\
\hline \multicolumn{4}{|l|}{ Sintomas Emocionais } \\
\hline Agitação & $26(24,5)$ & $80(75,5)$ & $106(100)$ \\
\hline Irritabilidade & $57(30,8)$ & $128(69,2)$ & $185(100)$ \\
\hline Insônia & $8(14,5)$ & $47(85,5)$ & $55(100)$ \\
\hline Desanimo & - & $13(100)$ & $13(100)$ \\
\hline Cansaço mental & - & 11(100) & $11(100)$ \\
\hline Tristeza & - & $12(100)$ & $12(100)$ \\
\hline Dificuldade de concentração & $11(30,6)$ & $25(69,4)$ & $36(100)$ \\
\hline
\end{tabular}

Para concluir a apresentação dos resultados, a Tabela 4 apresenta o cruzamento dos sintomas físicos e emocionais, referidos pelos participantes da pesquisa, associados ao uso de agrotóxicos, conforme a ocorrência de transtorno mental comum, com o uso do instrumento SRQ-20. Nesta verifica-se que ambos os sintomas, físicos e emocionais, foram mencionados pelos trabalhadores que apresentam o transtorno com maior intensidade comparados aos que não possuem.

Nesta verifica-se que os sintomas físicos mencionados pelos participantes que possuem transtorno mental comum em percentuais mais elevados, foram: náuseas, tontura, boca seca, dor de cabeça e irritação nos olhos. No que tange aos sintomas emocionais, estes compreenderam: insônia, agitação, dificuldade de concentração e irritabilidade.

\section{Discussão}

Os altos investimentos em agroquímicos têm refletido em todo cenário agrícola em ganhos na produção e prejuízos à saúde do agricultor. Os resultados apresentados do presente estudo apontam para alguns impactos do uso de agrotóxicos na saúde deste trabalhador.

Dos 361 trabalhadores rurais, participantes da pesquisa, constata-se que o fato de a maioria estar na faixa etária dos 40 aos 60 anos incompletos, vem ao encontro de outras pesquisas com população rural e que utiliza agrotóxicos nas lavouras (Benedetti et al., 2013; Viero et al., 2016). O agricultor mais jovem tinha 18 anos, e o mais velho, 73 anos. Esse dado remete ao preconizado na Norma Regulamentadora 
(NR) 31, na qual menores de 18 anos ou maiores de 60 anos não podem manusear agrotóxicos ou produtos afins (Ministério do Trabalho e Emprego, 2015). Quanto aos índices elevados de baixa escolaridade dos participantes da pesquisa e o fato de a maioria ser casada, igualmente é similar com achados da literatura (Menegat \& Fontana, 2010; Albuquerque et al., 2015; Savi, Sakae, Candemil, Sakae, \& Remor, 2010).

Dos 361 participantes da pesquisa, o fato de 173 agricultores apresentarem transtorno mental comum, é estatisticamente significativa $(\mathrm{p}<0,01)$ e diretamente relacionada com tempo de trabalho na agricultura, contato e exposição aos agrotóxicos. Esse resultado representa impacto provavelmente desencadeado pelo uso e exposição à agrotóxicos que vem ao encontro de pesquisa em comunidades rurais de Atibaia/SP. Esta mostra prevalência de transtornos mentais com as variáveis baixa escolaridade, problema de saúde, ter sofrido intoxicação por agrotóxico e carga horária de trabalho semanal (Lima et al., 2015).

Outro estudo que avaliou a relação entre prevalência de transtornos mentais menores em trabalhadores expostos a agrotóxicos no cultivo de tabaco, apontou que os que utilizaram organofosfatos apresentaram $50 \%$ mais risco de desenvolver o referido transtorno. Assim, evidencia-se neste a associação entre uso de agrotóxicos e comprometimento da saúde mental (Faria, Fassa, Meucci, Fiori, \& Miranda, 2014).

Na pespectiva dos danos dos agrotóxicos à saúde do agricultor, destaca-se a presença de transtorno mental associado a algumas doenças preexistentes, referidas pelos participantes deste estudo. As doenças mais citadas por eles também são alvo de outros resultados de estudos que contemplam esta população, tais como câncer, depressão, gastrite, problemas cardíacos, hipertensão, dentre outros (Beseler et al., 2008; Vanhaecht \& Palin, 2013; Sekhotha, Monyeki, \& Sibuyi, 2016).

Com relação à incidência de câncer em agricultores que utilizam agrotóxicos, estudos internacionais pontuam esta condição e afirmam que a exposição contínua a esses compostos químicos tem sido relacionada com vários tipos de câncer (Andreotti et al., 2009; Gawarammana \& Buckley, 2011; Salerno, Sacco, Panella, \& Berchialla).

Investigação em população rural do Sul do Brasil avaliou associação entre contato com agrotóxicos e prevalência de doenças crônicas em 298 pessoas que exerciam atividades rurais ou eram membros de famílias de agricultores. Os resultados revelaram que o contato direto ou indireto com agrotóxicos associa-se ao relato de várias doenças, sendo as neurológicas e as orais as mais prevalentes (Souza et al., 2011). Na perspectiva de adoecimento do trabalhador rural, estudo de coorte na Carolina do Norte contribui com seus achados e aponta significativa relação entre exposição ocupacional aos agroquímicos e a presença de sequelas neurológicas. Os resultados emergiram a partir da participação de 52.395 agricultores, e destacou a prevalência de depressão (Beseler et al., 2008).

A análise da ocorrência de gastrite e exposição aos compostos químicos agrícolas mostra tendência estatisticamente significativa deste comprometimento à saúde do agricultor. Dados da literatura evidenciam incidência de problemas gastrointestinais em $85 \%$ dos expostos e relaciona ao uso de duas aplicações de inseticidas por safra. Esse dado mostrou-se ainda maior em $167 \%$ quando os trabalhadores duplicaram a dose de herbicida utilizado (Pingali, 2012).

A presença de doenças cardiovasculares (DCV) em agricultores expostos a agrotóxicos mostra-se um efeito agressivo, conforme evidenciado nesta pesquisa, na qual $65 \%$ dos participantes relataram algum comprometimento. As DCVs, aparecem igualmente em outras pesquisas que associam práticas insalubres, manuseio dos agroquímicos, reveladas por infarto do miocárdio, insuficiência cardíaca congestiva, acidente vascular encefálico e arritmias induzidas pelas intoxicações agudas (Sekhotha, Monyeki, \& Sibuyi, 2016; Wahab, 2016). Em relação ao percentual de $58,6 \%$ dos participantes da pesquisa relatar ser hipertenso, esse resultado vai ao encontro de outros estudos que apontam o referido comprometimento, característico de população exposta aos agroquímicos (Menegat \& Fontana, 2010; Moreira, Oliveira, Muzi, Cunha, Brito, \& Luiz, 2015).

Analisadas as doenças referidas pelos 361 agricultores participantes desta pesquisa, destacam-se, igualmente, os sintomas mencionados por eles, associados à presença de transtorno mental comum e ao de uso de agrotóxicos no labor. Os sintomas físicos relatados foram: náuseas, tontura, boca seca, dor de cabeça e irritação nos olhos, divulgados também em outros estudos (Menegat \& Fontana, 2010; Mascarenha \& Pessoa, 2013). Esses resultados remetem à importância de o profissional de saúde estar atento a tais sintomas, visto que são vagos, subjetivos e que, na maioria das vezes, não são relacionados pelo trabalhador rural com o uso de agrotóxicos.

$\mathrm{Na}$ mesma proporção e intensidade dos sintomas físicos, ganham visibilidade os sintomas emocionais, tais como insônia, agitação, dificuldade de concentração e irritabilidade. Estes resultados, igualmente, são condizentes com outros estudos em população rural exposta a agrotóxicos (Goldberg \& Huxley, 1992; Faria et al., 2014; Lima, 2015). 
Com base nos resultados desta pesquisa aliados à literatura, evidencia-se que o trabalhador rural que utiliza agrotóxicos sofre danos à sua saúde física e psíquica. Para tanto, requer planejamento de ações da equipe multiprofissional referentes à atenção integral nos serviços de saúde.

\section{Considerações finais}

A utilização de agrotóxicos compromete a saúde física e psíquica do trabalhador rural. Salienta-se a ocorrência de transtorno mental comum em $47,9 \%$ dos participantes da pesquisa, com relação estatisticamente significante entre tempo de trabalho na agricultura, exposição aos agrotóxicos e doenças preexistentes. Além desses, os sintomas físicos e emocionais mais referidos pelos trabalhadores com TMC foram: náuseas, tontura, boca seca, dor de cabeça, irritação nos olhos, insônia, agitação, dificuldade de concentração e irritabilidade.

Os resultados desta pesquisa vão ao encontro da literatura, porém há necessidade de mais evidências científicas referentes ao comprometimento da saúde do trabalhador rural decorrente do uso de agrotóxicos, expressa pela gravidade das doenças e sintomas referidos pelos trabalhadores.

Enquanto profissional de saúde, especificamente da saúde mental, cabe ressaltar a necessidade de se considerar os indicativos deste estudo, a fim de fomentar discussões e ações acerca da temática principalmente no que tange ao modelo agrícola atual, que investe e prioriza o uso de agrotóxicos. Neste cenário o agricultor que busca permanecer no meio, faz o uso destas substâncias de forma forçosa a fim de produzir conforme o modelo vigente, na maioria das vezes, sem questionar-se sobre os efeitos deste comportamento.

Diante de todo exposto o que nos preocupa é o adoecimento físico e psíquico enquanto consequência de um uso irracional em que o agricultor torna-se um refém calado. Assim, os agrotóxicos lhes são apresentados como uma solução que traz somente benefícios a produção, pela ideologia do capitalismo, que visa o lucro. Em contrapartida além dos altos investimentos financeiros o trabalhador é sujeito ao comprometimento do seu bem maior, a saúde. E é por este triste cenário, que faz com que o agricultor permaneça a margem de tudo isso, que nós profissionais de saúde precisamos estar engajados, a fim de proporcionarmos debates e ações educativas. Precisamos voltar nosso cuidado ao ser humano que está em meio a esta mercantilização. Neste sentido, temos por compromisso sensibilizar os trabalhadores rurais que utilizam agrotóxicos, suas famílias e a comunidade quanto aos riscos decorrentes desta prática a fim de proteger e promover a saúde, em especial a mental em que os efeitos são tardios e na maioria das vezes irreversíveis.

Neste cenário em que encontramos o trabalhador rural enquanto centro, não podemos deixar de destacar o envolvimento da população geral pela exposição indireta pela água, ar e consumo dos alimentos, este contexto demonstra a abrangência da temática, enquanto uma questão social de saúde pública em que os órgãos fiscalizadores são negligentes. Precisamos reivindicar nossos direitos com relação a proteção humana e ambiental pelos órgãos federais, estaduais e municipais responsáveis.

Ao concluir esta escrita, verificamos o quanto é essencial não apenas priorizar os critérios de produção, mas a proteção da saúde dos trabalhadores rurais e a população num todo. A forma como tem sido disseminado o uso de agrotóxicos reforça a necessidade de ações relacionadas ao controle, fiscalização e ao esclarecimento dos efeitos deste uso indiscriminado. Neste enredo, destaca-se a importância da mobilização dos órgãos governamentais, de programas que incentivem outras formas de se produzir com menos agressividade direta à saúde do trabalhador e indireta a todos os consumidores. Nesta perspectiva proporcionar melhores condições de vida para os trabalhadores rurais, classe trabalhista, que é ao mesmo tempo, importante e invisível na nossa sociedade, bem como uma alimentação de qualidade que não cause riscos a população.

\section{Referências}

Abreu, P. H. B. \& Alonzo, H. G. A. (2014). Trabalho rural e riscos à saúde: uma revisão sobre o "uso seguro" de agrotóxicos no Brasil. Ciência \& Saúde Coletiva, 19(10), 4197-4208. http://dx.doi.org/10.1590/1413-812320141910. 09342014

Albuquerque, P. C. C. D., Gurgel, I., Gurgel, A., Augusto, L., \& Siqueira, M. (2015). Sistemas de informação em saúde e as intoxicações por agrotóxicos em Pernambuco. Rev Bras Epidemiol, 18(3), 666-78. http://dx.doi.org/10.1590/19805497201500030012

ANVISA. (2011). Agência Nacional de Vigilância Sanitária. Programa de Análise de Resíduo de Agrotóxico em Alimentos (PARA), dados da coleta e análise de alimentos de 2010. Brasília: ANVISA. http://portal.anvisa.gov.br/ 
Andreotti, G., Freeman, L. E. B., Hou, L., Coble, J., Rusiecki, J., Hoppin, J. A., \& Alavanja, M. C. (2009). Agricultural pesticide use and pancreatic cancer risk in the Agricultural Health Study Cohort. International journal of cancer, 124(10), 2495-2500. http://doi.org/10.1002/ijc.24185

Associação Brasileira da Indústria Química. (2014). O desempenho da indústria química brasileira em 2014. Disponível em: <http://www.?????????>. Acesso em: 8 set 2016.

Benachour, N. \& Séralini, G. E. (2008). Glyphosate formulations induce apoptosis and necrosis in human umbilical, embryonic, and placental cells. Chemical research in toxicology, 22(1), 97-105. http://doi.org/10.1021/tx800218n

Benedetti, D., Nunes, E., Sarmento, M., Porto, C., dos Santos, C. E. I., Dias, J. F., \& da Silva, J. (2013). Genetic damage in soybean workers exposed to pesticides: evaluation with the comet and buccal micronucleus cytome assays. Mutation Research/Genetic Toxicology and Environmental Mutagenesis, 752(1), 28-33. http://dx.doi.org/10.1016/j. mrgentox.2013.01.001

BESELER et al. (2008). Environmental Medicine Depression and Pesticide Exposures among Private Pesticide Applicators Enrolled in the Agricultural Health Study. Environmental Health Perspectives, 116(12), 1713-1719, 2008.

Brasil. Ministério da Saúde. (2016). Agrotóxicos na ótica do Sistema Único de Saúde. Brasília: Ministério da Saúde.

Cigana. (2016). Uso de agrotóxicos no Rio Grande do Sul chega quase ao dobro da média nacional. Disponível em: $<$ http://www.zerohora.clickrbs.com.br>. Acesso em: 26 jul. 2016.

Dossiê Abrasco. (2012). Um alerta sobre os impactos dos agrotóxicos na saúde. Parte 1 - Agrotóxicos, Segurança Alimentar e Nutricional e Saúde. Rio de Janeiro: ABRASCO. http://dx.doi.org/10.1590/1413-812320141910.09342014

Fareed, M., Pathak, M. K., Bihari, V., Kamal, R., Srivastava, A. K., \& Kesavachandran, C. N. (2013). Adverse respiratory health and hematological alterations among agricultural workers occupationally exposed to organophosphate pesticides: a cross-sectional study in North India. PLoS One, 8(7), e69755. http://dx.doi.org/10.1371/ journal.pone.0069755

Faria, N. M. X., Fassa, A. G., Meucci, R. D., Fiori, N. S., \& Miranda, V. I. (2014). Occupational exposure to pesticides, nicotine and minor psychiatric disorders among tobacco farmers in southern Brazil. Neurotoxicology, 45, 347-354. http://dx.doi.org/10. 1016/j.neuro.2014.05.002

Ferreira, M. J. M. \& Viana, M. M. (2016). The expansion of agribusiness in Ceará semiarid region and their implications for health, work and environment. Interface-Comunicação, Saúde, Educação, 20(58), 649-660. http://dx.doi. org/10.1590/1807-57622015.0029

Furlong, M., Tanner, C. M., Goldman, S. M., Bhudhikanok, G. S., Blair, A., Chade, A. \& Langston, J. W. (2015). Protective glove use and hygiene habits modify the associations of specific pesticides with Parkinson's disease. Environment international, 75, 144-150. http://doi.org/10.1016/j.envint.2014.11.002

Gawarammana, I. B. \& Buckley, N. A. (2011). Medical management of paraquat ingestion. British journal of clinical pharmacology, 72(5), 745-757. http://doi.org/10.1111/j.1365-2125.2011.04026.x

Gonçalves, D. M., Stein, A. T., \& Kapczinski, F. (2008). Avaliação de desempenho do Self-Reporting Questionnaire como instrumento de rastreamento psiquiátrico: um estudo comparativo com o Structured Clinical Interview for DSM-IVTR. Cad. Saúde Pública, 24(2):380-390. http://dx.doi.org/10.1590/S0102-311X2008000200017.

Goldberg, D. P. \& Huxley, P. (1992). Common mental disorders: a bio-social model. Tavistock/Routledge.

Lima. P. J. P. (2015). Prevalência de transtornos mentais comuns em comunidades rurais em Atibaia/SP - Brasil. Cad Brasileiros de Saúde Mental, 7(15): 101-121.

Londres, F. (2011). Agrotóxicos no Brasil: um guia para ação em defesa da vida. AS-PTA - Assessoria e Serviços a Projetos em Agricultura Alternativa, 190.

Mascarenha, F., Pessoa, Y. S. R. Q. (2013). Aspectos que potencializam a contaminação do trabalhador rural com agrotóxicos: uma revisão integrativa. Trabalho e Educação, 22(2): 87-103.

Menegat, R. P. \& Fontana, R. T. (2010). Condições de trabalho do trabalhador rural e sua interface com o risco de adoecimento Ciência, Cuidado e Saúde, 9(1), 52-59. http://doi.org/10.4025/cienccuidsaude.v9i1.7810

Merlo, A. R. C., Bottega, C. G., \& Perez, K. (2014). Atenção à saúde mental do trabalhador: sofrimento e transtornos

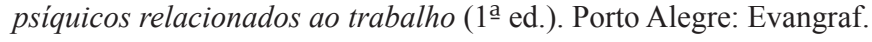

Ministério do Trabalho e Emprego. (2015). Portaria MTE no 86, de 03 de março de 2005. NR 31 - Segurança e saúde no trabalho na agricultura, pecuária silvicultura, Exploração florestal e agricultura. Disponível em: http://portal.mte. gov.br/data/files/8A7C812D33EF459C0134561C307E1E94/NR-31\%20(atualizada\%202011).pdf>. Acesso em: 04 out. 2016.

Miranda, N. M. (2015). Evidências dos efeitos dos agrotóxicos na carcinogênese. Revista da Graduação, 8(1).

Moreira, J. P. L., Oliveira, B. L. C. A., Muzi, C. D., Cunha, C. L. F., Brito, A. S., \& Luiz, R. R. (2015). A saúde dos trabalhadores da atividade rural no Brasil. Cadernos de Saúde Pública, 31(8), 1698-1708. https://dx.doi. org/10.1590/0102-311X00105114

Nodari, R. O. Guerra, M. P. Agroecologia: estratégias de pesquisa e valores. Estudos Avançados, 29(83), 183-207. http:// dx.doi.org/10.1590/S0103-40142015000100010

Pingali, P. L. (2012). Green revolution: impacts, limits, and the path ahead. Proceedings of the National Academy of Sciences, 109(31), 12302-12308. http://dx.doi.org/10.1073/pnas.1107959108 
Salerno, C., Sacco, S., Panella, M., Berchialla, P., Vanhaecht, K., \& Palin, L. A. (2013). Cancer risk among farmers in the Province of Vercelli (Italy) from 2002 to 2005: an ecological study. Annali di igiene: medicina preventiva e di comunita, 26(3), 255-263. http://dx.doi.org/10.7416/ai.2014.1983

Savi, E. P., Sakae, T. M., Candemil, R., Sakae, D. Y., \& Remor, K. V. T. (2010). Sintomas associados à exposição aos agrotóxicos entre rizicultores em uma cidade no sul de Santa Catarina. Arquivos Catarinenses de Medicina, 39(1).

Sekhotha, M. M., Monyeki, K. D., \& Sibuyi, M. E. (2016). Exposure to agrochemicals and cardiovascular disease: a review. International journal of environmental research and public health, 13(2), 229. http://doi.org/10.3390/ ijerph13020229

Souza, A. D., Medeiros, A. D. R., Souza, A. C. D., Wink, M. R., Siqueira, I. R., Ferreira, M. B. C. \& Torres, I. L. D. S. (2011). Avaliação do impacto da exposição a agrotóxicos sobre a saúde de população rural: Vale do Taquari (RS, Brasil). Ciência \& saúde coletiva. 16(8), 3519-3528. http://dx.doi.org/10.1590/S1413-81232011000900020

Viero, C. M., Camponogara, S., Cezar-Vaz, M. R., Costa, V. Z. D., \& Beck, C. L. C. (2016). Risk society: the use of pesticides and implications for the health of rural workers. Escola Anna Nery, 20(1), 99-105. http://doi. org/10.5935/1414-8145.20160014

Wahab, A. (2016). The effect of pesticide exposure on cardiovascular system: a systematic review. International Journal of Community Medicine and Public Health, 3(1), 1-10. http://dx.doi.org/10.1590/0102-311X00105114

Dados dos autores:

Pâmela Vione Morin - Mestre, Sociedade Educacional Três de Maio-RS - SETREM.

Eniva Miladi Fernandes Stumm - Doutora, Sociedade Educacional Três de Maio-RS - SETREM.

Endereço para correspondência:

Pâmela Vione Morin

Santo Antônio, Consolata - interior

98910-000, Três de Maio, RS, Brasil

<pamelamorin@bol.com.br>

Recebido em: 06.03.2017

Aceito em: 04.08.2017 